Penultimate draft; final version published in The Monist 97.4 (2014), 460-478.

\title{
IN DEFENCE OF EXISTENCE QUESTIONS
}

\section{Chris Daly and David Liggins, University of Manchester}

\section{Introduction}

Do numbers exist? Do properties? Do possible worlds? Do fictional characters? Many metaphysicians spend time and effort trying to answer these and other questions about the existence of various entities. These inquiries have recently encountered opposition: a group of philosophers have argued that many or all of the existence questions debated by metaphysicians can be answered trivially, and so are not worth debating. Jonathan Schaffer argues that 'contemporary existence debates are trivial, in that the entities in question obviously do exist' (Schaffer 2009: 357, his italics). Kit Fine (2009: 158-9) argues that, whilst the debate over the existence of concrete possible worlds may be non-trivial, this is an exceptional case: the existence questions debated by metaphysicians typically have trivial answers. Kathrin Koslicki (2012: 186) suggests that metaphysicians' existence questions can often be answered trivially: for example, the correct answer to 'Do numbers exist?' is 'Yes, of course'.

Koslicki claims that a 'significant reorientation' of analytic metaphysics is taking place. She associates Quine with the attempt to answer existence questions, and claims that metaphysicians are moving away from Quinean metaphysics. In her view, they are moving towards an approach she associates with Aristotle, which emphasizes the importance of questions about dependence. Rather than investigating whether, for example, there are smiles, supporters of this approach investigate whether smiles depend on mouths. In the same spirit, Schaffer proposes that metaphysicians should concentrate on investigating what grounds what, describing this as a 'more traditional Aristotelian view' of metaphysics. Here Schaffer echoes earlier work of Fine's (2001). Both Fine and Koslicki contribute chapters to a recent volume entitled Contemporary Aristotelian Metaphysics (Tahko ed. 2012). Let us therefore call Koslicki, Fine, and Schaffer 'the neo-Aristotelians'.

There is currently an explosion of work on dependence - especially non-causal dependence, or grounding, as it is often known. ${ }^{1}$ At the same time, many philosophers are sceptical about these inquiries, and some of this scepticism has been expressed in print. ${ }^{2}$ In this paper, we will stay neutral on whether questions about what grounds what are worthy of philosophical attention. Our task is to defend existence questions from the neo-Aristotelians' attacks.

\footnotetext{
${ }^{1}$ Clark and Liggins 2012 and Trogdon 2013 trace the developments.

${ }^{2}$ See Hofweber 2009 and Daly 2012.
} 
Outside of philosophy, there are many non-trivial existence questions: for example, consider the controversies concerning the existence of Hitler's diary, Higgs bosons, Iraqi weapons of mass destruction, cold fusion reactors, the Yeti, and extraterrestrial intelligence. We encounter many non-trivial existence questions in our everyday life: for instance, we might not know whether there exists a book in the library which addresses a certain problem, or whether, in this shop, there exists a suitable present for my aunt. We would therefore expect the same to go for philosophy, in that many of the existence questions debated within philosophy are non-trivial. Since the neoAristotelians deny this, the burden of argument lies with them.

In sections 2 and 3 we examine the neo-Aristotelians' arguments and find them wanting. In section 4 we argue that Schaffer's responses to objections are weak. In this way, we defend existence questions, and the philosophers who work on them, from their neo-Aristotelian critics.

\section{Post-Moorean modesty}

According to Schaffer, it is obvious that the entities in question exist. The existence of numbers is immediately entailed by something which is obviously true: that there are prime numbers. Similarly, Schaffer holds that the existence of properties follows from the 'everyday truism' (2009: 358) that there are properties you and I share. And so on for all of the entities whose existence is the subject of metaphysical debate.

Schaffer responds to some objections which seek to show that these inferences are invalid. For the sake of argument, let us grant Schaffer their validity, and consider the prospects for replying to these arguments by denying the truisms in question.

In Schaffer's opinion, the truism that there are prime numbers 'commands Moorean certainty, as being more credible than any philosopher's argument to the contrary' (2009: 357, his italics). Here Schaffer approvingly cites Fine:

[I]n this age of post-Moorean modesty, many of us are inclined to doubt that philosophy is in possession of arguments that might genuinely serve to undermine what we ordinarily believe.

It may perhaps be conceded that the arguments of the skeptic appear to be utterly compelling; but the Mooreans among us will hold that the very plausibility of our ordinary beliefs is reason enough for supposing that there must be something wrong in the skeptic's arguments, even if we are unable to say what it is. (Fine 2001: 2) 
As we have mentioned, Fine is more circumspect than Schaffer: Fine allows that the debate over the existence of concrete possible worlds may be non-trivial. Presumably that is because he thinks our ordinary beliefs neither entail that these entities exist nor entail that they do not exist. But Fine and Schaffer agree that many existence questions are easily answered by our ordinary beliefs. Their view is that, for many existence questions, there is some ordinary belief which (i) entails an answer to the question and (ii) which is more certain than the conjunction of the premises of any countervailing argument which a metaphysician might put forward.

We will now argue that these considerations fail: appeal to post-Moorean modesty does not establish that a single contemporary existence debate concerns a trivially answerable question.

What do Fine and Schaffer mean when they talk of truisms and ordinary beliefs being 'credible' and 'plausible'? They cannot just mean that they are highly confident in ordinary beliefs, such as that there are prime numbers, or that there are properties that you and I share. That is because such psychological claims do not on their own establish anything epistemologically significant. The neo-Aristotelians are not merely reporting their own psychological states but claiming that the ordinary beliefs are exceptionally strongly justified - so strongly justified that no metaphysician could defeat them by argument. But it remains to be shown why we should think the beliefs have such a high degree of justification.

To make the argument work, neo-Aristotelians need to show that the beliefs have this special epistemic status. What could establish that strong conclusion? Since the neo-Aristotelian view is intended to cover many or all of the existence questions debated by metaphysicians, they need to appeal to a general principle. The most obvious option is for them to appeal to some principle of epistemic conservatism, such as the principle that if you believe something, you are thereby justified in continuing to believe it.

There are two problems with this option. First, the justification in question is defeasible. Faced with a strong argument against an ordinary belief, it would be dogmatic to insist on holding on to the belief on the ground that one already possesses it. Sufficiently strong evidence could overturn any ordinary belief. For instance, Aristotle and his contemporaries found it obvious that the Earth does not move, but their belief was refuted by the scientific evidence. It would have been absurd to reject the scientific arguments for earthly motion by asserting that their conclusion is obviously false.

The second problem is that the principle of epistemic conservatism does not credit ordinary beliefs with a sufficiently high degree of justification. There are no arguments to show that if you believe something, you are thereby exceptionally strongly justified in continuing to believe it. But 
the neo-Aristotelians' argument requires that our ordinary beliefs are exceptionally strongly justified.

So if the justification is not exceptionally strong, and is also defeasible, why think that metaphysicians cannot come up with strong enough evidence to defeat it? Earlier in his article, Fine rejects 'the assumption that philosophy is able to provide us with some special reasons for doubting what we ordinarily accept' (2001: 2), but he does not explain what he means by 'special reasons', or argue for this rejection other than in the passage quoted above. Similarly, Schaffer asserts that philosophers' arguments lack credibility relative to Moorean certainties, as we have seen - but he does not explain what it is about philosophers' arguments which given them this lowly status.

We regard the allusion to Moore as misleading. Since Moore was arguing against murky Hegelian denials of the existence of the external world, the allusion suggests that metaphysicians deny ordinary beliefs on the basis of obscure and ill-motivated doctrines. Whilst some metaphysicians may argue that way, it is clear that they do not all do. Metaphysicians appeal to the same sorts of premises as other philosophers. Quite generally, the best arguments start from plausible premises. Neither do metaphysicians employ any unfamiliar or esoteric forms of inference. Fine is therefore right to deny that philosophy provides special reasons for doubting ordinary beliefs. Ordinary reasons suffice. Neither Fine nor Schaffer has offered an argument to show that philosophers cannot supply ordinary reasons.

Many philosophers think of reflective equilibrium as the correct philosophical method. (DePaul 1998 argues that it is the only rational philosophical method.) In reflective equilibrium we try to turn our stock of beliefs into as theoretically virtuous a collection as possible. This may well involve adding further beliefs, but equally it might involve discarding some beliefs in order to make the collection more virtuous, all things considered. Even if we count conservatism as a virtue - that is, even if we think that a collection which preserves pre-theoretical beliefs as more virtuous therebyit may be that the collection which is most virtuous overall is one which is not especially conservative. That is because there are virtues other than conservatism which a philosophical theory may possess (consistency, simplicity, explanatory power, etc.) and all virtues must be taken into account when a collection is assessed. On a reflective equilibrium approach to philosophy, it is not guaranteed that the best collection will incorporate most of our pre-theoretical beliefs. Still less is it guaranteed that it will incorporate all of them. As Lewis writes, expounding reflective equilibrium: 'Sometimes common sense may properly be corrected, when the earned credence that is gained by making theory more systematic more than makes up for the inherited credence that is lost' (1986: 134) (see also Quine 1981: 72 and Daly and Liggins 2010: section 4). 
This discussion makes it clear how a philosophical argument may overturn an ordinary belief without citing any distinctively philosophical reason for denying it. The argument may simply cite the ordinary sort of reason: that its denial is part of the theory which is most virtuous overall.

Let us illustrate the point. According to Schaffer (2009: 357 n. 8), philosophical arguments against the existence of numbers 'typically involve substantive causal and/or epistemic theses, aimed to show that entities like numbers would have to be causally inert or epistemically inaccessible'. Schaffer goes on to claim that 'mathematical truisms such as ['There are prime numbers'] deserve far greater credence than any causal and/or epistemic philosophical dictums they may conflict with'. Schaffer has in mind here arguments such as the following:

If numbers exist, then we have arithmetical knowledge.

We have arithmetical knowledge only if we are causally related to numbers.

We are not causally related to numbers.

Therefore, numbers do not exist.

(Benacerraf 1973: section IV puts forward an argument of this sort.) The second premise of the argument places a causal constraint on arithmetical knowledge. Since this premise is less obvious than the conclusion, it may be that the argument is best regarded as a reductio of the premise (see Lewis 1986: 108-9).

For convenience, we will grant that the arguments Schaffer regards as typical really are so. Since Schaffer's conclusion is that there is no good philosophical argument against the existence of numbers, it is insufficient for him to discuss only the typical arguments against their existence - for perhaps the non-typical arguments are successful. We will now present an argument against the existence of numbers and show that it escapes Schaffer's objection. The argument is based on Field (1989: 25-30, 68-9, 230-9).

If there are numbers, then mathematicians have many true mathematical beliefs about them. But if so, then how is the accuracy of these beliefs to be explained? The challenge is hard to meet: since numbers are not causally active, there is no causal explanation; but no adequate non-causal explanation is available either. If we deny that there are numbers, we avoid this explanatory deficit. Indeed, this improvement in explanatory power outweighs the diminished conservativeness, so by denying the existence of numbers we make our theory more virtuous overall. 
This argument avoids any general claim about the relation between causation and knowledge. It contains no philosophical 'dictum' corresponding to the second premise of the previous argument. As a consequence, it escapes Schaffer's objection. ${ }^{3}$

The argument illustrates the point we made earlier: it does not offer any special philosophical reasons for doubting the existence of numbers, but only an ordinary sort of reason - that, all things considered, our account of the world will be superior if we deny that there are numbers. The argument does assume that considerations of explanatory power can outweigh considerations of conservatism, but then we have never been supplied with an argument to disprove this. ${ }^{4}$

Venting his post-Moorean modesty, Fine writes: 'in so far ... as the pretensions of philosophy to provide a world-view rest upon its claim to be in possession of the epistemological high ground, those pretensions had better be given up' (Fine 2001: 2). We regard Fine's talk of 'pretentions' and 'high ground' as unhelpfully rhetorical. More importantly, Fine's claim is misplaced, given that his principal target, and that of the other neo-Aristotelians, is Quine. For Quine famously denies that philosophy occupies 'the epistemological high ground': he characterizes philosophy as 'not as an $a$ priori propaedeutic or groundwork for science' but 'continuous with science'. According to Quine, 'There is no external vantage point, no first philosophy' (Quine 1969: 126-7). Fine thus mischaracterises his leading opponent's position, and this leads to a failure to engage with the holistic epistemology Quine actually proposed. We have shown that metaphysicians who work on existence questions can disavow any claim to the epistemological 'high ground' whilst reserving the right to deny ordinary beliefs and everyday truisms.

\section{Interdisciplinary deference}

As we have seen, Schaffer says that the claim that there are prime numbers 'commands Moorean certainty'. But he also describes the claim as a 'mathematical truism' (2009: 357). Similarly, Schaffer describes the claim that my body has proper parts (hands, for example) as a 'biological banality', and goes on to argue that it is clear that there exist things with proper parts (2009: 358). These descriptions hint at a different way to argue for the triviality of contemporary existence debates. The idea is that some or all of these debates can be settled by appeal to our best theories from other disciplines, such as mathematics or biology: these debates are trivial, since our best theories in these areas entail the existence of the relevant entities. Fine echoes this idea when he claims

\footnotetext{
${ }^{3}$ See also Liggins 2006 and and Liggins 2010: 70-5.

${ }^{4}$ For a critical survey of philosophical arguments against ordinary beliefs, see Daly and Liggins 2010.
} 
that the question of whether there are numbers is 'a mathematical question ... that is to be settled on the basis of purely mathematical considerations', and says that scientists have the job of settling whether there are atoms (2009: 169).

Many philosophers would agree that appeal to mathematics provides a strong case for the existence of numbers. But that does not show that the debate over the existence of numbers is trivial - for perhaps there is a strong case against the existence of numbers. And the same goes for appeal to biology and other disciplines to settle existence questions. To establish that an existence debate is trivial in this fashion, it must be that the theory from outside philosophy provides so strong a case for a particular answer to the existence question that it cannot be defeated by any other considerations to which a philosopher might appeal. Above we examined the suggestion that ordinary beliefs cannot be overturned by philosophical arguments; now we must examine the suggestion that results from other disciplines cannot be overturned by philosophical arguments.

The first thing to note about the suggestion is that it is implausible. Let us confine our attention for the time being to mathematics and the natural sciences. We all agree that these disciplines are of immense value, that they are among our proudest intellectual achievements, and they deserve a large measure of respect. But none of those platitudes entails that these disciplines provide reasons for belief which are philosophically indefeasible. That is a much stronger claim: it goes beyond respect for these disciplines, and substitutes unquestioning deference. Those who make that stronger claim owe us an argument for it.

There is a second reason to think that the suggestion is implausible. It implies that philosophical reflection cannot help us to correct our best theories from other areas. But it is a platitude that careful reflection on a group of beliefs can help to improve them. Proponents of the suggestion are committed to the striking view that less thinking is better, so far as discovering the truth is concerned. Perhaps they think that there is a special problem with the sort of philosophical reflection practiced by metaphysicians. If so, then we can only repeat the remarks made in the previous section. Perhaps they think that those who reject the suggestion have to make the hubristic claim that some philosophers are better at mathematics than mathematicians, or better at biology than biologists. If so, then we can only point out that this does not follow, since to engage in philosophical reflection is not to engage in mathematics or biology.

Since the suggestion is implausible, the burden of proof rests on those who make it: only if there is a compelling argument in its favour should we endorse the suggestion. But no such argument has been given. 
Schaffer (2009: 357 n. 8) cites David Lewis's comment that he is 'moved to laughter at the thought of how presumptuous it would be to reject mathematics for philosophical reasons' (Lewis 1991: 59). The passage from which this comment is drawn is the one most often cited by philosophers seeking to justify deference to mathematics. Although Lewis (1991: 59) claims not to be offering an argument, his remarks certainly suggest an argument in support of Schaffer's attitude:

How would you like the job of telling the mathematicians that they must change their ways, and abjure countless errors, now that philosophy has discovered that there are no classes? Can you tell them, with a straight face, to follow philosophical argument wherever it may lead? If they challenge your credentials, will you boast of philosophy's other great discoveries: that motion is impossible, that a being than which no greater can be conceived cannot be conceived not to exist, that it is unthinkable that anything exists outside the mind, that time is unreal, that no theory has ever been made at all probable by evidence (but on the other hand that an empirically ideal theory cannot possibly be false), that it is a wide-open scientific question whether anyone has ever believed anything, and so on, and on ad nauseam? Not me! (Lewis 1991: 59)

The argument proceeds by comparing the track records of mathematics and philosophy. The comparison is supposed to establish that mathematics has a better track record than philosophy. Does Lewis's litany of heroic philosophical failures establish that it would be presumptuous, or otherwise bad, for philosophers to deny our best mathematical theories?

We do not think it does. The Lewisian argument has been subjected to careful discussion in the subsequent literature, and the consensus is that the argument fails. Here we will summarize two of the most significant complaints.

The first objection is that the argument is a crude induction. Perhaps philosophy as a whole has a bad track record. But that does not imply that every part of philosophy has a bad track record. Philosophy's heroic failures were the results of bad arguments. If we can identify what made those arguments bad, and show that metaphysicians' arguments do not share these defects, then we can defend these philosophers' work from the Lewisian argument. For instance, take Popper's argument that no amount of evidence can make an unfalsified theory probable. If I reject the standards of argument which Popper relied on in reaching this conclusion, and thereby reject some of Popper's premises or inferential moves - then, as Paseau 2008: section 4.5 puts it, 'the fact that 
his then philosophy of science is from my point of view manifestly wrong does nothing to shake my faith in my own philosophical standards'. Even if the track record of philosophy has a whole is inferior to the track record of biology or mathematics, that does not imply that contemporary metaphysicians' arguments are inferior to the arguments of contemporary biologists or mathematicians. It remains to be shown that the arguments of contemporary metaphysicians share the defects which led Popper and others into error. ${ }^{5}$

Moreover, it is unclear that disciplines such as mathematics and biology have a better track record than philosophy when it comes to answering the existence questions debated by metaphysicians. Typically mathematicians and scientists presuppose some philosophically controversial existence claims, which are reflected in the theories they come up with. Schaffer's examples will serve here: mathematicians and mathematical theories presuppose that there are numbers; biologists and biological theories presuppose that there are parts. Now mathematicians do not spend any time addressing the question of whether there are numbers, any more than biologists spend time discussing the questions of whether there are parts. There are no mathematical arguments for the existence of numbers: that there are numbers is an assumption of mathematics, not one of its conclusions. Anyone who scours mathematics textbooks for a proof of the existence of numbers is bound to be disappointed. ${ }^{6}$ (That is why it is misleading for Fine to describe the question of whether there are numbers as 'to be settled on the basis of purely mathematical considerations'.) Few mathematicians or scientists are familiar with the philosophical debates concerning these matters, and even fewer have been trained to contribute to these debates. On the other hand, their theories may have been influenced by philosophical theories which philosophers now reject. For instance, quantum mechanics may reflect instrumentalism in the philosophy of science, which is now unpopular (see Lewis 1987: xi and Dorr 2010: 160-1). So when we focus on the existence questions debated by metaphysicians, it is far from clear that we should regard mathematics or science as having a superior track record to philosophy.

In the words of Mark Balaguer:

In short, there are not many mathematicians who have very much expertise on these issues, and so it seems to me that there is nothing immodest, to use Burgess's term, about

\footnotetext{
${ }^{5}$ See also Paseau 2005 and Daly and Liggins 2011: 326.

${ }^{6}$ 'But didn't Euclid prove that there are infinitely many primes?' No: he proved a conditional - that, if there exist prime numbers, there exist infinitely many of them. By the same reckoning, earlier mathematicians had proved only that, if there are numbers, there are prime numbers. No mathematician has proved that there are numbers.
} 
philosophers telling mathematicians what they ought to say about these issues. Indeed, just the opposite seems true, for it is philosophers who are the experts here. They are the ones who have been trained to address questions like this and who focus on these questions professionally. (2009: 155; see also Dorr 2010: 151-2)

We maintain that precisely the same goes for empirical scientists such as biologists. Their training fits them to answer biological questions, not metaphysical ones. Those who are immodest are not the metaphysicians who debate answers to existence questions, but those philosophers who suppose that these debates can be settled merely by citing what mathematical or scientists say. For it is immodest to claim that that is the one and only consideration relevant to the debate.

Now if a scientific theory's empirical failure could ever be traced to false metaphysical assumptions, then scientists would be in a position to deny these assumptions. But the existence questions debated by metaphysicians are seldom directly empirically testable in this way, and it is controversial whether they are empirically testable in any way. So we should expect that metaphysical assumptions will remain part of scientific theories regardless of whether these assumptions are true or false. ${ }^{7}$

The first objection, then, is that once we focus on the specific questions at issue, and on the specific community of philosophers labouring to answer them, the Lewisian argument is revealed to be a crude induction.

The second objection is simpler: the argument threatens to prove too much. The Lewisian argument is not meant to cast doubt on philosophy as a whole, but only on those philosophical claims which conflict with results from other disciplines. But the argument, if successful, does show that philosophy as a whole cannot establish any conclusions. It is an attempt to discredit the reliability of philosophical arguments in general. So the argument as it stands proves too much. The defender of the argument needs to persuade us of the (implausible) claim that philosophy is dubious only when its results conflict with mathematics or science. ${ }^{8}$

It is notable that, although Schaffer cites Lewis with approval, he does not discuss these or any of the other objections that have been levelled at the Lewisian argument.

Although the Lewisian argument is the principal argument that has been offered in support of the claim that results from other disciplines cannot be overturned by philosophical arguments, some other arguments have been made as well. For instance, one might appeal to the fact that

\footnotetext{
${ }^{7}$ For a case study, see Daly and Liggins 2013.

${ }^{8}$ See Leng 2005: 282 and Daly and Liggins 2011: 327-8.
} 
there is much more agreement among mathematicians and scientists than among philosophers. We lack the space to discuss these here but refer the reader to the criticisms of these arguments made in Paseau 2008: section 4, and Daly and Liggins 2011.

So far we have argued that it is implausible that the results from other disciplines cannot be overturned by philosophical arguments, and we have suggested that there is no compelling argument for this conclusion. To finish this section, we will present an unsolved problem for the view.

The problem concerns the basis on which disciplines are singled out for the extreme degree of respect which Schaffer proposes. What is it about astrology and biology that makes it permissible for philosophers to contradict the former but not the latter (Rosen 1999; Rosen 2001: 81-2)? Penelope Maddy (1997: 184) has tried to answer this question by claiming that 'successful' disciplines are immune from philosophical criticism. But what is 'success' here? If Maddy means 'success by the discipline's own standards', then any discipline, no matter how dubious, could render itself immune from philosophical criticism by lowering its standards until it counts itself as successful - and that would be absurd. But it is hard to find another conception of success which will serve Maddy's purpose. ${ }^{9}$ To the best of our knowledge, the questions of which disciplines deserve this degree of respect, and why, have never received adequate answers.

To summarize: the claim that debates over existence questions are settled by 'mathematical truisms' and 'biological banalities' is implausible, lacks a secure motivation, and raises a difficult unsolved problem.

\section{Schaffer's replies}

So far we have argued that the triviality of the existence questions debated by metaphysicians has not been established by appeal to post-Moorean modesty, nor by appeal to interdisciplinary deference. In this section we argue that Schaffer's responses to objections are weak.

The dispensability argument. Schaffer (2009: 360) considers the objection that there are ways of eliminating entities from our best theories. For instance, Field 1980 offers a way of removing reference to mathematical entities from scientific theories. Perhaps Field's reformulated theories are superior to the originals, in which case the motivation for claiming that numbers exist is diminished, and so the existence of numbers is not so trivial after all.

\footnotetext{
${ }^{9}$ See Paseau 2008: sections 4.3 and 5.2 and Daly and Liggins 2011: 336.
} 
Schaffer's reply to this objection is to distinguish proposals such as Field's from the 'Quinean gloss' they might be given. Schaffer maintains that if Field's reformulation succeeds, then it shows 'how numbers do exist in a world of concrete substances, as grounded in certain features of such substances', such as relations between spacetime points. He claims that this interpretation of Field's work is superior to the rival interpretation on which it contributes to the debate over the existence of numbers, because it renders Field's reformulation consistent with the 'obvious fact' that there are prime numbers (2009: 360).

It is very difficult to make sense of the interpretation Schaffer is proposing. Field's reformulations of scientific theories make no mention of numbers or grounding, so it is hard to see how they 'show' (Schaffer's word) that numbers are grounded in the concrete. The reformulated theories do not have the right form to be interpreted as theories about the grounding of numbers. According to Schaffer, 'The question for those who would want to retain the eliminativist construal of such constructions is why?' (2009: 360 n. 14, Schaffer's italics). The question for them to ask Schaffer is what is the proposed alternative?

We wonder whether Schaffer would say the same in other cases where entities are apparently eliminated from theories. The discovery that the best explanation of combustion does not imply the existence of phlogiston is generally taken to show that phlogiston does not exist. Would Schaffer say that it established that phlogiston does exist after all, grounded in other things? Copernican astronomy was supposed to avoid the Ptolematic postulation of epicycles. Would Schaffer say that Copernican astronomy actually vindicates the existence of epicycles and tells us about their grounds? Would he claim that naturalistic explanations of apparent miracles in fact support the existence of the supernatural? We do not think that these suggestions are plausible, and we fail to see why the case of Field's programme is any different.

As part of a response to this criticism, Schaffer might claim the following epistemic difference: the existence of numbers is obvious, whereas empirical inquiry has revealed that there is no reason to believe in the existence of phlogiston and epicycles. But Schaffer cannot take this route. By his lights, the existence of failed posits follows immediately from the banal observation that some failed posits are difficult to detect. Schaffer's other commitments require him to believe in phlogiston and epicycles. Given what he says about God - that God exists and is a fictional character (2009: 359) - we would expect Schaffer to say that the scientific question about phlogiston and epicyles is not whether they exist, but whether they are fictional. So Schaffer cannot respond to our objection by citing the epistemic difference mentioned above. 
Fine's response to dispensability arguments is along these lines: he maintains that we have reasons to believe in mathematical objects which have nothing to do with their role in explanation. ' $[T]$ he fact that there are no goblins is reason enough to think that the number of goblins is 0 (and hence that there is a number)' (Fine 2009: 160). Here Fine seems to appeal to the neo-Fregean philosophy of mathematics associated with Neil Tennant, Crispin Wright, and Bob Hale. The neoFregean view is highly controversial, and that is enough to undercut Fine's contention that the existence of numbers is a trivial matter. ${ }^{10}$

Intuitions of unreality. According to Schaffer, it is trivial that fictional characters exist: it follows from the 'literary fact' that Conan Doyle created Sherlock Holmes. Schaffer acknowledges that we have, as he puts it, 'countervailing intuitions of unreality': it is natural to say that Sherlock Holmes does not exist (Schaffer 2009: 359, 360).

Schaffer attempts to accommodate these intuitions by invoking the familiar phenomenon of quantifier domain restriction. When I say 'Everything is in the picnic basket', I do not make the absurd claim that everything whatsoever is in the basket. Rather, the context narrows down the domain of my utterance, for instance, to those things that are required for the picnic, so that I claim that everything needed for the picnic is in the basket. Schaffer does not spell out his suggestion in detail: in particular, he does not mention which restriction he thinks is operative when we claim 'Holmes does not exist'. There are various possible alternatives: if we restrict the domain to the entities that are not fictional characters, for instance, or the entities that are mind-independent, then plausibly 'Holmes does not exist' will come out as true, even if - unrestrictedly speaking Holmes does exist.

The same defence has been tried by other philosophers who hold that fictional characters exist, including Amie Thomasson and Alberto Voltolini. But it is subject to a powerful objection, due to Kendall Walton (2003: 240-1) and Anthony Everett (2007: 67). Their point is that there is a subtle difference between claims of the form 'There are Fs' and claims of the form 'Fs exist': the former are subject to quantifier domain restriction, but the latter are not. For instance, suppose I inspect the contents of my garage and discover there is no bicycle there. Then it is appropriate to say 'There is no bicycle', but inappropriate to say 'Bicycles do not exist'. In the circumstances, the former has a true reading on which it claims that there is no bicycle in the garage. But 'Bicycles do not exist' does not have a true reading in these circumstances. (If you deny the existence of bicycles, please change the example.) The same goes for names: if $N$ exists outside the domain of

\footnotetext{
${ }^{10}$ Wright and Hale (2001: 421-36) list eighteen outstanding problems; MacBride 2003 surveys the many critical responses to neo-Fregeanism. See also Ebert and Rossberg (forthcoming).
} 
quantification, it is inappropriate to say ' $N$ does not exist'. The consequences are clear: while 'There is no such thing as Holmes' might be an example of quantifier domain restriction, 'Holmes does not exist' is not - and so Schaffer cannot defend his theory by appeal to that phenomenon. Schaffer does not discuss this objection. ${ }^{11}$

Contradicting the dicta. Schaffer (2009: 361) considers the further objection that his view violates 'some crucial methodological, epistemological, or metaphysical dictum'. The methodological dictum he discusses is Occam's Razor. Schaffer admits that his ontology is extremely abundant but maintains that it does not fall foul of this dictum. His defence is that the Razor should be understood to concern just those entities which do not have a ground. Following Schaffer, let us call these 'fundamental' entities. In Schaffer's view, we should minimize the number of fundamental entities, but it does not matter how many non-fundamental entities we posit; since Schaffer does not claim that there is an abundance of fundamental entities, he takes it that his view escapes the Razor.

Schaffer then considers two objections together: that his postulation of entities we cannot experience offends against 'empiricist scruples'; and that his postulation of abstract entities contradicts 'nominalistic demands'. Here his strategy is to argue that his view can accommodate the scruples and demands in question. Let us quote the whole of his reply:

Empiricist scruples and nominalistic demands may be met if the entities in question are grounded. For instance, if numbers are indeed grounded in the concrete realm, then (i) they may be known via their concrete grounds, and (ii) they would be brought down to earth. (Schaffer 2009: 361)

Schaffer's replies to these objections all involve the notion of grounding. For the sake of argument, we will grant that grounding-talk is intelligible. Even making this concession, we regard Schaffer's replies as weak, for reasons we will now explain.

In the case of Occam's Razor, Schaffer admits that his view runs into trouble with the principle as it is usually formulated, and goes on to reformulate it to avoid the trouble. Since we are supplied with no further argument, this modification is an ad hoc manoeuvre. We are given no reason at all to doubt the usual formulation of Occam's Razor, and so no reason to think that Schaffer's view is

\footnotetext{
${ }^{11}$ Everett 2007 presents objections to other proposals for accommodating the intuitions, short of denying the existence of fictional characters, and argues that the evidence favours a theory according to which there are no fictional characters.
} 
out of trouble. Admittedly, Schaffer links his view to previous debate by quoting Armstrong's phrase 'the ontological free lunch', but it is far from clear that Armstrong has established Schaffer's favoured version of the Razor. ${ }^{12}$

In section 2, we encountered Field's epistemological argument against the existence of abstract entities. Schaffer's reply to such worries about the abstract entities he posits amounts to the suggestion that we know about these entities known via the concrete entities which ground them. As it stands, this suggestion is not substantial enough to be successful. To begin with, it raises the question: which concrete entities ground the numbers? Schaffer does not tell us, so it is difficult for us to accept that these entities, whatever they are, serve as the source of our arithmetical knowledge. Schaffer does say (2009: 375) that each singleton set is grounded by its member, so probably he thinks that we can gain knowledge of a singleton - for instance, the knowledge that Helen's singleton exists - by coming to know about its member - Helen, in this case. But we are given no hint of how knowing about Helen would help us discover that there is a set of which she is the sole member.

Moreover, the suggestion is implausible, for in other cases it seems that grounding lacks the epistemological implications Schaffer needs. General doubts about grounding aside, it is plausible that cases of realization are cases of grounding: for instance, it may be that our mental states are grounded in the neurophysiological states of our brains. But we cannot come to know what mental state someone is in merely by knowing what neurophysiological state their brain is in. We cannot come to know of correlations between mental and neurophysiological states merely by knowing the neurophysiological states: independent access to the mental states is required (Williamson 1994: 204). In this case, knowing the ground is insufficient for knowing the grounded. Now perhaps there are other cases where knowing the ground suffices for knowing the grounded, but Schaffer needs to establish that, and show that knowledge of abstract entities conforms to this pattern. Schaffer's brief proposal is tantalizing, but it is very far from constituting an acceptable epistemology of the abstract.

Finally, Schaffer's response to 'nominalistic demands' is to say that providing grounds for abstract entities 'brings them down to earth'. We are unsure what Schaffer has in mind here. If the nominalistic demand is 'Do not posit abstract entities', then the postulation of abstract entities that are grounded clearly fails to meet the demand. Perhaps Schaffer intends to treat this worry in a similar way to the Occam's Razor objection: he might assert that there is no need to meet the

\footnotetext{
${ }^{12}$ See David 2005: section 3 for commentary on the 'ontological free lunch'. For further criticism of Schaffer on Occam's Razor, see Daly 2010: 97-8 and Clark 2012: section 4.4.
} 
demand 'Do not posit abstract entities', and that his theory meets the more reasonable demand 'Do not posit ungrounded abstract entities'. But then the same worry arises as before: until we are given a reason to think that the first demand is unreasonable, the assertion establishes nothing. Many philosophers who deny the existence of abstract entities will back up their denial by citing Occamist or epistemological objections; and we have already argued that Schaffer's attempts to overcome these objections are unsuccessful.

\section{Conclusion}

We have argued that the neo-Aristotelians' arguments for the triviality of existence questions are unpersuasive, and we have argued that Schaffer's replies to objections are weak. Perhaps the neoAristotelians are right to commend the study of grounding - on that issue, we have remained neutral. But they are wrong to deprecate ontology as the study of trivial questions. ${ }^{13}$

\section{Works cited}

Balaguer, Mark 2009. Fictionalism, theft, and the story of mathematics. Philosophia Mathematica 17: 131-162.

Benacerraf, Paul 1973. Mathematical truth. Journal of Philosophy 70: 661-79.

Chalmers, David J., David Manley, and Ryan Wasserman (eds) 2009. Metametaphysics: New Essays on the Foundations of Ontology. Oxford: Clarendon Press.

Clark, Michael J. 2012. The Metaphysics of Grounding. Ph. D. Thesis, University of Manchester. Clark, Michael J. and David Liggins, David 2012. Recent work on grounding. Analysis 72: 812-823. Daly, Chris 2010. An Introduction to Philosophical Methods. Peterborough, Ontario: Broadview Press.

Daly, Chris 2012. Scepticism about grounding. In Fabrice Correia and Benjamin Schnieder (eds) Metaphysical Grounding: Understanding the Structure of Reality. Cambridge: Cambridge University Press: 81-100.

Daly, Chris and David Liggins, David 2010. In defence of error theory. Philosophical Studies 149: 209-230.

Daly, Chris and David Liggins 2011. Deferentialism. Philosophical Studies 156: 321-337.

Daly, Chris and David Liggins 2013. Animalism and deferentialism. Dialectica 67: 605-9.

${ }^{13}$ Thanks to audiences at the University of Lille, the Vrije Universiteit Amsterdam, and the University of Manchester. 
David, Marian 2005. Armstrong on truthmaking. In Helen Beebee and Julian Dodd (eds)

Truthmakers: The Contemporary Debate. Oxford: Clarendon Press: 141-59.

DePaul, Michael R. 1998. Why bother with reflective equilibrium? In Michael R. DePaul and William Ramsey (eds) Rethinking Intuition: The Psychology of Intuition and Its Role in Philosophical Inquiry. Lanham: Rowman and Littlefield: 293-309.

Dorr, Cian 2010. Of numbers and electrons. Proceedings of the Aristotelian Society 110: 133-81. Ebert, Philip and Marcus Rossberg (forthcoming). Abstractionism. Oxford: Oxford University Press. Everett, Anthony 2007. Pretence, existence, and fictional objects. Philosophy and Phenomenological Research 74: 56-80.

Field, Hartry 1980. Science without Numbers. Oxford: Basil Blackwell.

Field, Hartry 1989. Realism, Mathematics and Modality. Oxford: Basil Blackwell.

Fine, Kit 2001. The question of realism. Philosopher's Imprint 1.

URL=<philosophersimprint.org/001001/>

Fine, Kit 2009. The question of ontology. In David J. Chalmers, David Manley, and Ryan Wasserman (eds) 2009: 157-177.

Fine, Kit 2012. What is metaphysics? In Tuomas E. Tahko (ed.) 2012: 8-25.

Hale, Bob and Crispin Wright 2001. The Reason's Proper Study: Essays Towards a Neo-Fregean Philosophy of Mathematics. Oxford: Clarendon Press.

Hofweber, Thomas 2009. Ambitious, yet modest, metaphysics. In David J. Chalmers, David Manley, and Ryan Wasserman (eds) 2009: 260-89.

Koslicki, Kathrin 2012. Varieties of ontological dependence. In Fabrice Correia and Benjamin Schnieder (eds) Metaphysical Grounding: Understanding the Structure of Reality. Cambridge: Cambridge University Press: 186-213.

Leng, Mary 2005. Revolutionary fictionalism: a call to arms. Philosophia Mathematica 13: 277-293. Lewis, David 1986. On The Plurality of Worlds. Oxford: Basil Blackwell.

Lewis, David 1987. Philosophical Papers: Volume II. New York: Oxford University Press. Lewis, David 1991. Parts of Classes. Oxford: Basil Blackwell.

Liggins, David 2006. Is there a good epistemological argument against platonism? Analysis 66: 135141.

Liggins, David 2010. Epistemological objections to platonism. Philosophy Compass 5:67-77. MacBride, Fraser 2003. Speaking with shadows: a study of neo-logicism. British Journal for the Philosophy of Science 54: 103-163.

Maddy, Penelope 1997. Naturalism in Mathematics. Oxford: Clarendon Press. 
Paseau, Alexander 2005. Naturalism in mathematics and the authority of philosophy. British Journal for the Philosophy of Science 56: 377-396.

Paseau, Alexander 2008. Naturalism in the philosophy of mathematics. In Edward N. Zalta (ed.) The Stanford Encyclopedia of Philosophy (Winter 2008 Edition). URL = <http://plato.stanford.edu/archives/win2008/entries/naturalism-mathematics/>.

Quine, W.V. 1969. Ontological Relativity and Other Essays. New York: Columbia University Press.

Quine, W. V. 1981. Theories and Things. Cambridge, MA: Belknap Press.

Schaffer, Jonathan 2009. On what grounds what. In David J. Chalmers, David Manley, and Ryan Wasserman (eds) 2009: 347-383.

Tahko, Tuomas E. (ed.) 2012 Contemporary Aristotelian Metaphysics. Cambridge: Cambridge University Press.

Trogdon, Kelly 2013. An introduction to grounding. In Miguel Hoeltje, Benjamin Schnieder and Alex Steinberg (eds) Varieties of Dependence: Ontological Dependence, Grounding, Supervenience, Response-Dependence. Munich: Philosophia Verlag: 97-122.

Walton, Kendall L. 2003. Restricted quantification, negative existentials, and fiction. Dialectica 57: 241-4.

Williamson, Timothy 1994. Vagueness. London: Routledge. 